\title{
Síntese e caracterização de precursores de cério de alta pureza
}

\section{(Synthesis and characterization of high purity cerium precursors)}

\author{
C. A. S. Queiroz ${ }^{1}$, D. M. Avila ${ }^{2}$, A. Abrão $o^{1}$, E. N. S. Muccillo ${ }^{2}$ \\ ${ }^{1}$ Departamento de Engenharia Química e Ambiental \\ ${ }^{2}$ Departamento de Engenharia de Materiais \\ Instituto de Pesquisas Energéticas e Nucleares \\ C. P. 11.049 - Pinheiros - 05422-970, S. Paulo, SP \\ cqueiroz@net.ipen.br,enavarro@usp.br
}

\begin{abstract}
Resumo
Neste trabalho são destacadas as técnicas de separação e de purificação de terras raras por precipitação fracionada e troca iônica, além das técnicas usualmente utilizadas no controle analítico destes materiais. A aplicação destas técnicas é mostrada neste trabalho para a obtenção de óxido ou nitrato de cério com pureza $>99 \%$. O principal objetivo é a obtenção de precursores à base de cério para o processamento de cerâmicas de zircônia-céria ou céria contendo terras raras. A disponibilidade de cloretos mistos, matéria-prima para a preparação de terras raras individuais, e o conhecimento das técnicas de separação, purificação e controle analítico de terras raras no IPEN, permite sua obtenção local para uso em pesquisa e desenvolvimento.
\end{abstract}

Palavras-chave: cério, troca iônica, precipitação fracionada, precursores cerâmicos, síntese de materiais.

\section{INTRODUÇÃO}

Os elementos das terras raras constituem um grupo cujo nome mostra ser inadequado uma vez que o cério, o mais abundante, apresenta uma concentração na crosta terrestre superior à do cobre. As terras raras ocupam uma posição particular na tabela periódica, apresentando uma estrutura idêntica das camadas eletrônicas $5 \mathrm{~d}$ e $6 \mathrm{~s}$. Suas diferenças estão relacionadas com o progressivo preenchimento do subnível eletrônico $4 \mathrm{f}$.

Na Natureza as terras raras estão amplamente espalhadas, mas concentrações economicamente viáveis são pouco freqüentes. $\mathrm{O}$ Brasil possui uma das dez maiores reservas mundiais conhecidas de óxidos de terras raras [1].

A utilização das terras raras na indústria é muito ampla abrangendo áreas como a metalurgia, vidros, cerâmicas, eletrônica, iluminação, nuclear, química, médica, odontológica e farmacêutica. Como exemplo das várias aplicações destacam-se: na metalurgia, as superligas. Na tecnologia de vidros, em polimento, coloração, lentes ópticas e vidros de alta pureza para fibras ópticas. Em cerâ-

\begin{abstract}
In this work techniques of fractioned precipitation and ion exchange for separating and purifying rare earth elements are outlined. Other techniques usually utilized in the analytical control of these elements are also briefly discussed. The application of these techniques for the preparation of cerium nitrate or cerium oxide of $>99 \%$ purity are demonstrated. The main purpose is to obtain cerium precursors for the processing of zirconia-ceria or ceria-rare earth ceramic materials. The raw material availability in the form of mixed chlorides, and the knowledge of these techniques at IPEN allows for obtaining these precursors in the local market for research and development purposes.
\end{abstract}

Keywords: cerium, ion exchange, fractioned precipitation, ceramic precursors, synthesis of materials. micas, são utilizadas em capacitores cerâmicos de multicamadas, como pigmentos, nas cerâmicas avançadas e supercondutores cerâmicos de alta temperatura crítica. Na eletrônica e em iluminação, podem ser citados os imãs permanentes, os sensores de zircônia estabilizada com ítria, o recobrimento fluorescente de televisores em cores, lâmpadas fluorescentes e lasers. Na química, muito importantes são os catalisadores de craqueamento, automotivos e de polimerização, agente redutor, na produção de titânio, na espectroscopia, etc. Na área biomédica sua utilização está fundamentada em novas tecnologias como o suturamento com laser de neodímio, a bio-rotulação com térbio e európio e outras. Cerâmicas transparentes à base de óxido de berílio $(\mathrm{BeO})$ dopadas com

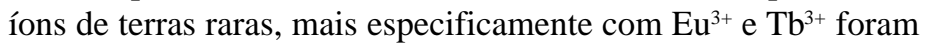
obtidas recentemente. A elevada afinidade das terras raras por oxigênio conduz à formação dos óxidos correspondentes, introduzindo novas propriedades à cerâmica através da formação de vacâncias, e melhorando o rendimento quântico da luminescência do BeO. Outro exemplo de emprego de terras raras em cerâmicas é na dopagem da alumina com óxido de cério e lantânio. Este tipo de 
material cerâmico vem sendo muito aplicado como catalisador, quando dopado também com metais nobres como Pt, Pd e Rh.

A utilização das terras raras está muito concentrada ainda na metalurgia, em vidros e na catálise. Um dos maiores problemas enfrentados pela indústria é o alto custo relacionado com o grau de pureza necessário para a elaboração do produto final. A indústria de terras raras distingue três graus de pureza: o da mistura, na composição que normalmente se verifica nos minérios; o dos concentrados, produzidos por simples reações de precipitação e que geralmente contêm de $60 \%$ a 90\% do elemento desejado; e o dos óxidos de terras raras puros contendo entre $98 \%$ e $99,999 \%$. Na indústria do aço, em catalisadores de craqueamento e em polimento de vidros, aplicações de larga escala, são utilizados misturas ou concentrados de terras raras.

No Brasil, a produção industrial em larga escala baseia-se principalmente na exploração mineral da monazita, encontrada nas areias monazíticas do litoral. Toda produção brasileira é proveniente da monazita industrializada na INB (Indústrias Nucleares Brasileiras). No entanto, a produção ainda restringe-se à separação das terras raras totais na forma de cloretos mistos.

Os elementos constituintes das terras raras apresentam acentuada semelhança de comportamento físico e químico, o que dificulta muito a separação de cada um deles. Os processos clássicos mais usados para a separação são cristalização fracionada, precipitação fracionada, óxido-redução, formação de complexos e precipitação posterior. Atualmente, são utilizados métodos associados de extração com solventes e troca iônica para a obtenção de lantanídeos de alta pureza.

No IPEN explora-se há muito tempo a separação das terras raras por ambos processos, procurando atender a demanda interna em áreas de pesquisa e desenvolvimento [2-4]. O principal objetivo deste trabalho é a obtenção do óxido ou nitrato de cério de pureza $>99 \%$ pelas técnicas de precipitação fracionada e troca iônica.

\section{EXPERIMENTAL}

\section{Técnicas de Síntese}

Para a síntese do cério nas formas de nitrato ou de óxido foram utilizadas as técnicas de precipitação fracionada e troca iônica.

\section{Precipitação Fracionada}

A técnica da precipitação fracionada foi utilizada neste trabalho para a separação do cério explorando-se a facilidade de sua oxidação ao estado tetravalente e a hidrólise do $\mathrm{Ce}^{4+}$ característica deste elemento.

A Fig. 1 apresenta as etapas de preparação do óxido de cério $(\sim 85 \%)$ a partir de um concentrado de terras raras. O cério é separado dos demais lantanídeos na forma de hidróxido, diretamente na solução de cloretos mistos de terras raras. $\mathrm{O} \mathrm{Ce}^{3+}$ é oxidado a $\mathrm{Ce}^{4+}$ pela adição controlada de peróxido de hidrogênio para, em seguida, ser hidrolizado e precipitado. A acidez liberada na hidrólise foi neutralizada fazendo-se passar um fluxo de amônia $\left(\mathrm{NH}_{3}\right)$ na solução. O precipitado, após filtração, é dissolvido em ácido clorídrico a quente, para ser estocado na forma de cloreto de Ce (III), para o tratamento subseqüente por troca iônica.

\section{Troca Iônica}

A técnica de troca iônica é muito eficiente na separação e purificação dos lantanídeos a partir de concentrados enriquecidos. Nesse

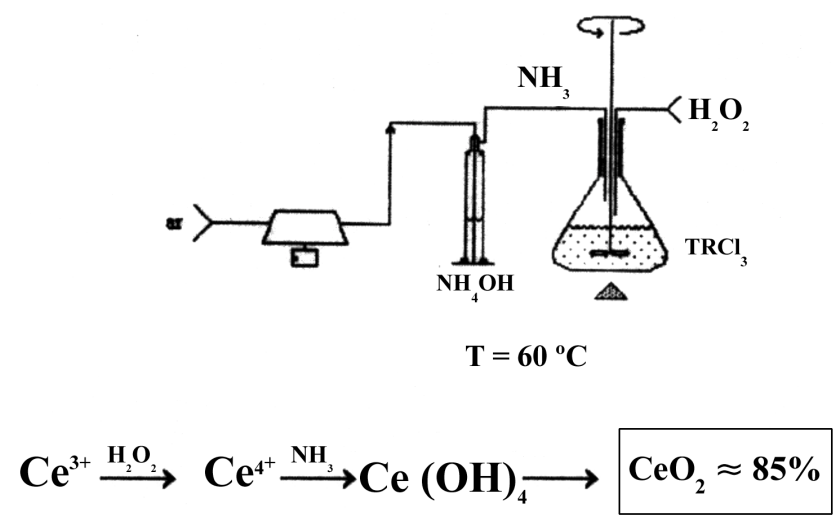

Figura 1: Etapa de preparação do $\mathrm{CeO}_{2}(80-90 \%)$ a partir do concentrado de terras raras por precipitação fracionada.

[Figure 1: Preparation of $\mathrm{CeO}_{2}$ (80 to 90\%) from a rare earth concentrate by the fractioned precipitation technique].

método, uma solução contendo as terras raras atravessa o leito de uma coluna contendo resina de troca iônica catiônica na forma $\mathrm{NH}_{4}^{+}$.

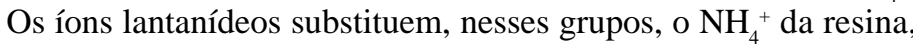
sendo então retidos por ela:

$$
\mathrm{M}^{3+}+3 \mathrm{NH}_{4}^{+}(\text {resina }) \rightarrow \mathrm{M}(\text { resina })_{3}+3 \mathrm{NH}_{4}^{+}
$$

A seguir, a resina é lavada com água deionizada para remover os íons $\mathrm{NH}_{4}^{+}$intersticiais. Para a eluição dos íons metálicos da coluna num processo seletivo, é utilizada uma solução de sal de amônio do ácido etilenodiaminotetracético (EDTA). Este é um eluente muito utilizado no fracionamento das terras raras, inclusive industrialmente, por ser de fácil recuperação e reciclagem. Desta forma, é estabelecido o equilíbrio:

$\mathrm{M}(\text { resina })_{3}+3\left(\mathrm{NH}_{4}\right)-$ EDTA $\leftrightarrow 3 \mathrm{NH}_{4}$-resina $+\mathrm{M}($ EDTA $)$

Na Fig. 2 é mostrada esquematicamente a etapa de fracionamento das terras raras por troca iônica.

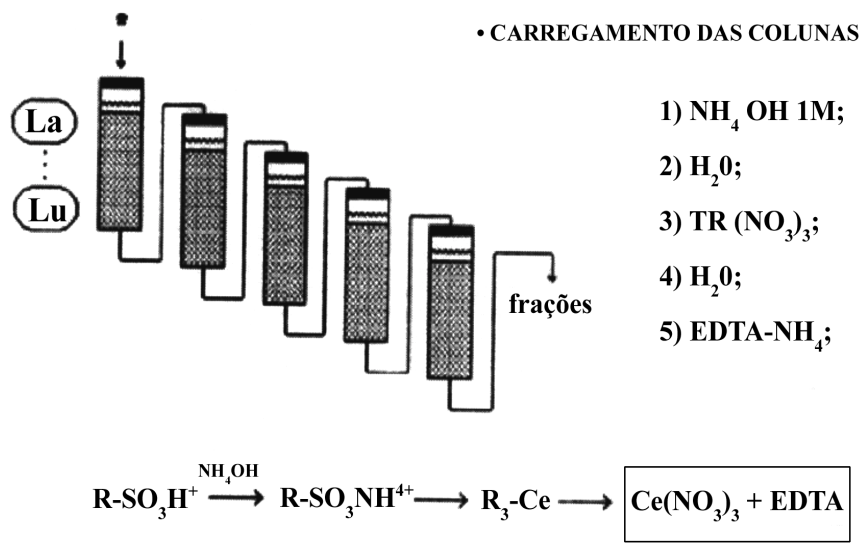

Figura 2: Etapa de preparação do nitrato ou óxido de cério de alta pureza (>99\%) por troca iônica.

[Figure 2: Preparation of high-purity (>99\%) cerium nitrate or cerium oxide by ion exchange technique]. 
À medida que a solução de EDTA percorre a coluna, os íons metálicos são dessorvidos da resina, passando para a solução na forma de complexos com o EDTA, e são readsorvidos pela resina um pouco mais abaixo. O processo é repetido muitas vezes, e o íon metálico atravessa pouco à pouco toda a coluna. Os íons lantanídeos hidratados menores, como o lutécio, formam complexos mais estáveis com o EDTA do que os íons maiores, como o lantânio. Assim, os íons menores e mais pesados permanecem mais tempo na solução e menos tempo na coluna. Consequentemente, os íons mais pesados são eluídos primeiro e, em condições adequadas, todos os elementos podem ser removidos separadamente da coluna, pelo processo cromatográfico e desta forma, obtidos como frações individuais $[5,6]$.

Na Fig. 3 é apresentado o fluxograma completo de preparação do nitrato e do óxido de cério pelas técnicas de precipitação fracionada e troca iônica.

Neste trabalho foram utilizadas 5 (cinco) colunas em série, medindo cada uma $100 \mathrm{~cm}$ de altura e $5 \mathrm{~cm}$ de diâmetro (ca. 2 litros de resina), com capacidade de retenção aproximada de $170 \mathrm{~g}$ de óxido cada. Foi utilizada a resina catiônica S-100 Bayer, 50-100

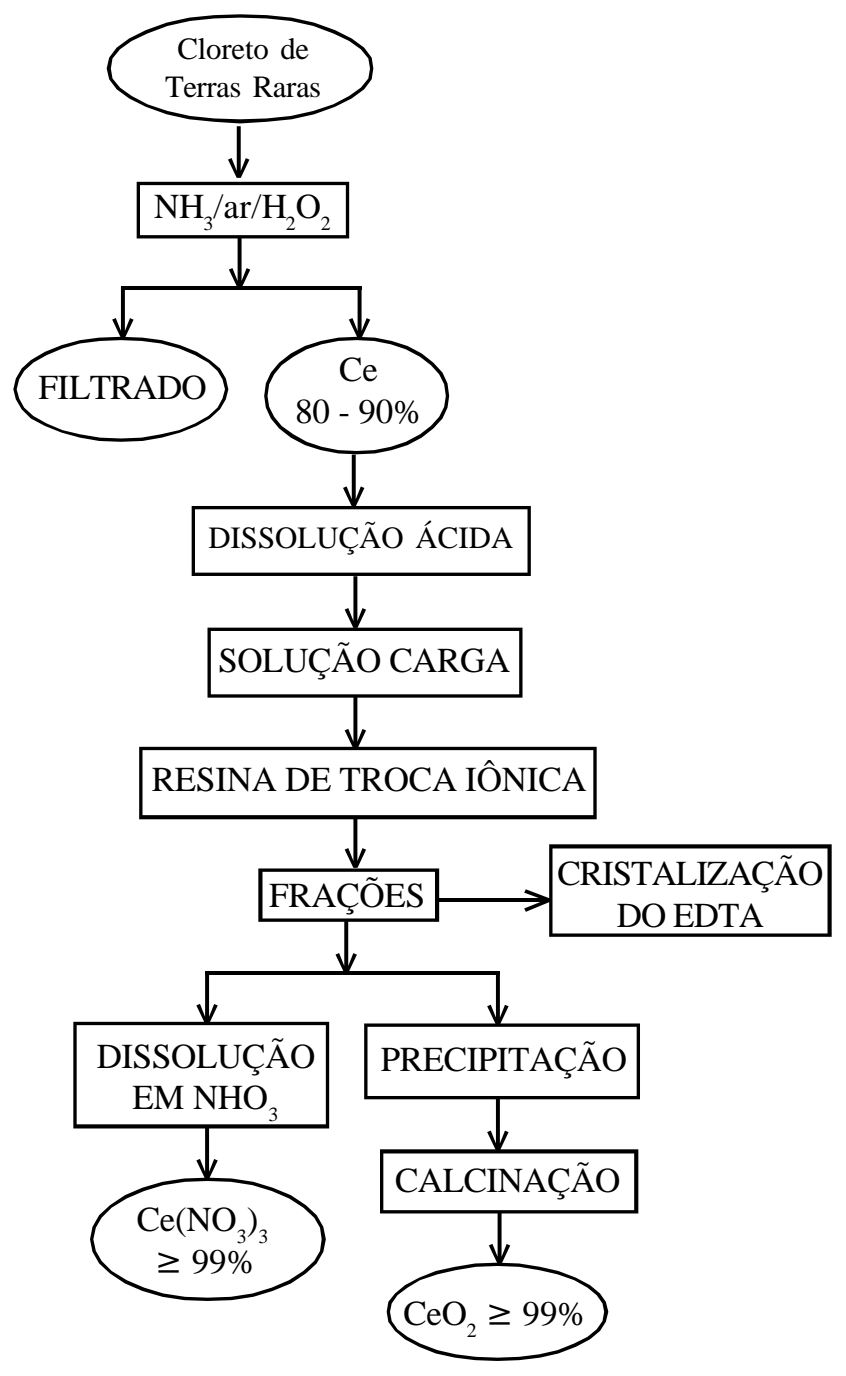

Figura 3: Fluxograma das etapas de preparação de compostos de cério pelas técnicas de precipitação fracionada e troca iônica.

[Figure 3: Flow chart for the preparation of cerium compounds by fractioned precipitation and ion exchange techniques]. mesh, forma amônio. Após lavagem e condicionamento da resina, foi preparada uma solução carga a partir do concentrado de terras raras contendo $\sim 85 \%$ em óxido de cério. Foram pesados $393 \mathrm{~g}$ desse material e adicionados ao ácido nítrico contendo um pouco de água oxigenada, para garantir a redução total do cério a Ce (III). Foi obtida uma solução de concentração igual a 8 g.L $L^{-1}$ de óxidos de terras raras para a alimentação do sistema, após diluição com água deionizada. Em seguida, foi acertado o pH 3,4 e a solução foi percolada na resina catiônica forte, mantendo-se a vazão entre $6 \mathrm{e}$ $8 \mathrm{~mL} \cdot \mathrm{min}^{-1}$. A resina foi lavada com água deionizada e, posteriormente, foi percolada a solução de EDTA, obtida a partir de soluções estoque de 300 g.L.-1 em EDTA.

\section{Controle Analítico}

O controle analítico foi feito utilizando as técnicas de iodometria e gravimetria. Foram feitas também determinações de impurezas metálicas por espectrometria de emissão com fonte de plasma acoplado indutivamente (ICP-AES) e determinação quantitativa de teores de terras raras por análise por ativação com nêutrons térmicos. O procedimento desta última consistiu em irradiar cerca de 20 mg de cada amostra por $8 \mathrm{~h}$ num fluxo de nêutrons de $\sim 10^{12} \mathrm{n} . \mathrm{cm}^{-}$ ${ }^{2} \cdot \mathrm{s}^{-1}$. As medidas da radiação gama induzida foram realizadas em um espectrômetro de raios gama, em duas etapas, sendo a primeira 15 dias após a irradiação e a segunda após 45 dias.

\section{Gravimetria}

Na técnica gravimétrica as terras raras em solução são precipitadas com ácido oxálico a quente. Após resfriamento da mistura, os oxalatos de terras raras são separados por filtração, secos e calcinados a $900^{\circ} \mathrm{C} / 1 \mathrm{~h}$. O óxido final é então pesado.

\section{Iodometria}

Esta técnica trata da titulação do iodo liberado em reações químicas. Neste trabalho o óxido de cério foi transformado em sulfato. Para isto, $0,1 \mathrm{~g}$ de óxido foi transferido para um Erlenmeyer de $500 \mathrm{~mL}$, sendo então adicionado $5 \mathrm{~mL}$ de ácido sulfúrico concentrado. A solução foi evaporada até a secura e este procedimento foi repetido mais duas vezes. Os sulfatos em solução de $\mathrm{H}_{2} \mathrm{SO}_{4} 2 \%$ foram aquecidos até a solubilização completa. Em seguida, a solução foi levada a um volume de $250 \mathrm{~mL}$, sendo adicionados nitrato de prata e persulfato de sódio e aquecida à ebulição durante 20 minutos. Essa solução foi titulada em pH $2 \mathrm{com}$ uma solução de amido como indicador do ponto final.

\section{Caracterizações}

A decomposição térmica de uma alíquota de uma das frações obtidas foi estudada por análise termogravimétrica (Shimadzu, TGA $50 \mathrm{H})$ com velocidade de aquecimento de $5^{\circ} \mathrm{C}$. $\min ^{-1}$ até $100{ }^{\circ} \mathrm{C}$ sob fluxo de ar sintético e velocidade de resfriamento de $15^{\circ} \mathrm{C} \cdot \mathrm{min}^{-1}$.

Após secagem e calcinação de uma amostra, a fase cristalográfica predominante foi obtida por difratometria de raios X (Rigaku, Geigerflex) com radiação do $\mathrm{Cu} \mathrm{K}_{\alpha}$ a $40 \mathrm{kV}$ e $20 \mathrm{~mA}$ usando filtro de $\mathrm{Ni}$ e com velocidade de varredura de $2^{\circ} 2 \theta \mathrm{min}^{-1}$.

$\mathrm{O}$ valor da superfície específica foi determinado, após calcinação, pelo método do BET (Quantachrome, Nova). A forma 
e o tamanho das partículas resultantes foram observados em microscópio eletrônico de varredura (Philips, XL30). A distribuição de tamanho de partículas foi obtida por espalhamento laser (Cilas, granulômetro mod. 1064).

\section{RESULTADOS E DISCUSSÃO}

Os resultados obtidos no balanço de massa na purificação do cério por troca iônica são apresentados na Tabela I.

Tabela I: Balanço de massa e condições de eluição na purificação do cério.

[Table I: Mass balance and experimental conditions used for cerium purification].

\begin{tabular}{lccccc}
\hline Fração & $\begin{array}{c}\text { Tempo } \\
(\mathrm{h})\end{array}$ & $\begin{array}{c}\text { Volume } \\
(\mathrm{L})\end{array}$ & $\mathrm{pH}$ & $\begin{array}{c}\text { Massa } \\
(\mathrm{g})\end{array}$ & $\begin{array}{c}\text { Vazão } \\
\left(\mathrm{mL}^{-m_{n}}{ }^{-1}\right)\end{array}$ \\
\hline 1 & 72 & 35 & 3,16 & 28,0 & 8,0 \\
\hline 2 & 53 & 31 & 3,18 & 78,0 & 8,0 \\
\hline 3 & 49 & 27 & 3,18 & 111,0 & 7,5 \\
\hline 4 & 89 & 47 & 3,05 & 129,8 & 8,0 \\
\hline 5 & 29 & 12 & 2,94 & 132,8 & 6,0 \\
\hline 6 & 44 & 17 & 3,00 & 137,6 & 6,0 \\
\hline 7 & 71 & 33 & 3,25 & 171,6 & 6,5 \\
\hline 8 & 24 & 11 & 3,33 & 185,8 & 7,0 \\
\hline 9 & 31 & 15 & 3,18 & 198,1 & 6,0 \\
\hline 10 & 24 & 12 & 3,24 & 206,5 & 7,0 \\
\hline 11 & 24 & 12 & 3,33 & 219,5 & 7,0 \\
\hline 12 & 67 & 22 & 3,29 & 244,8 & 8,0 \\
\hline 13 & 30 & 11 & 3,24 & 270,1 & 6,0 \\
\hline 14 & 24 & 11 & 3,25 & 287,1 & 6,0 \\
\hline 15 & 24 & 02 & 3,28 & 300,6 & 6,0 \\
\hline 16 & 45 & 16 & 3,25 & 303,4 & 6,5 \\
\hline 17 & 24 & 14 & 3,39 & 329,6 & 6,5 \\
\hline 18 & 24 & 15 & 3,25 & 341,4 & 6,5 \\
\hline
\end{tabular}

Nesta Tabela, o volume indicado corresponde ao volume coletado e a massa está na forma cumulativa.

De cada uma das frações contidas nesta Tabela foi retirada uma alíquota para se fazer uma determinação qualitativa da pureza do cério. A determinação se baseia na coloração do material. Para isto, cada alíquota foi precipitada com ácido oxálico e calcinada a $900{ }^{\circ} \mathrm{C} / 1 \mathrm{~h}$.

O óxido de cério puro apresenta uma cor amarelo clara. Até a fração 07 foram observados óxidos de coloração ocre, indicando contaminação no cério. Essas frações foram armazenadas e poderão ser utilizadas numa próxima purificação, pois o teor de cério é superior a $90 \%$. Uma avaliação da eficiência da técnica de troca iônica pode ser feita comparando as determinações quantitativas dos teores de $\mathrm{CeO}_{2}$ em duas frações consecutivas quaisquer. As frações 03 e 04 , por exemplo, apresentaram os valores $95,7 \%$ e $97,8 \%$ de $\mathrm{CeO}_{2}$, respectivamente.

$\mathrm{O}$ difratograma de raios $\mathrm{X}$ mostrado na Fig. 4 também exemplifica a eficiência das técnicas de síntese adotadas neste trabalho. Uma alíquota da fração 07, que ainda apresentou coloração ocre devido à contaminação com outros elementos de terras raras, foi seca e calcinada a $900^{\circ} \mathrm{C} / 1 \mathrm{~h}$. O perfil de difração obtido apresenta os picos característicos do óxido de cério (JCPDS 34-394), que possui estrutura cúbica tipo fluorita (grupo espacial Fm3m). Como o nível de contaminação nesta fração é inferior a $1 \%$, o resultado obtido está dentro do esperado de acordo com a limitação desta técnica de caracterização.

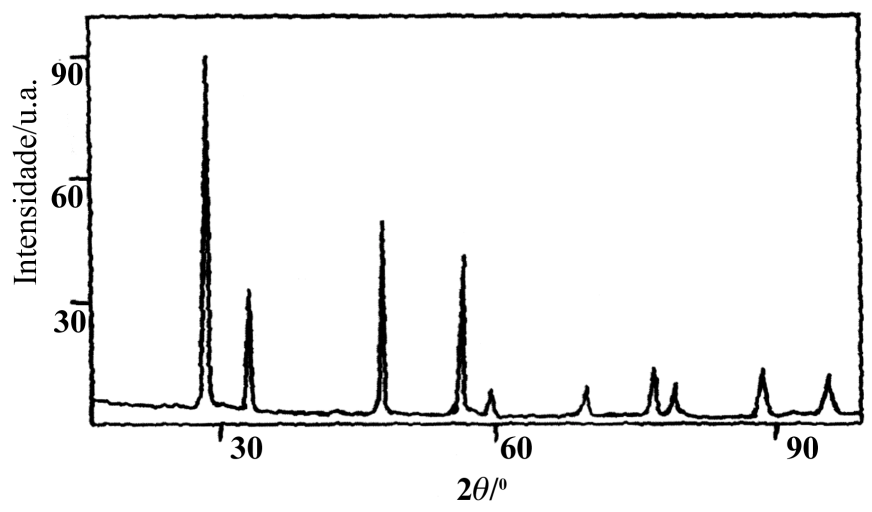

Figura 4: Difratograma de raios X de uma alíquota da fração 07 calcinada. [Figure 4: X-ray diffraction pattern of a calcined sample from fraction 07].

A fração 08 apresentou uma coloração típica do óxido de cério puro. Por isto, após a separação do EDTA, a massa de terras raras e o teor real de cério foram determinados por gravimetria e iodometria, respectivamente. Os resultados obtidos são apresentados na Tabela II, onde o volume mencionado corresponde ao volume total de cada fração.

Tabela II: Resultados das análises de gravimetria e iodometria na purificação do cério.

[Table II: Gravimetry and iodometry results obtained in the cerium purification].

\begin{tabular}{lcccc}
\hline Fração & $\begin{array}{c}\text { Volume } \\
(\mathrm{mL})\end{array}$ & $\begin{array}{c}\text { Massa de } \\
\mathrm{CeO}_{2}(\mathrm{~g})\end{array}$ & $\begin{array}{c}\text { Teor de } \\
\mathrm{Ce}(\%)\end{array}$ & $\begin{array}{c}\text { Teor de } \\
\mathrm{CeO}_{2}(\%)\end{array}$ \\
\hline 8 & 1670 & 14,2 & 81,0 & $\geq 99,0$ \\
\hline 9 & 940 & 12,3 & 81,1 & 99,6 \\
\hline 10 & 890 & 8,4 & 81,0 & $\geq 99,0$ \\
\hline 11 & 655 & 13,0 & 81,0 & 99,5 \\
\hline 12 & 775 & 25,3 & 81,1 & 99,6 \\
\hline 14 & 730 & 17,0 & 81,1 & 99,6 \\
\hline 15 & 550 & 13,5 & 81,4 & 99,99 \\
\hline 16 & 705 & 2,8 & 80,7 & 99,13 \\
\hline 17 & 750 & 26,2 & 80,5 & 98,9 \\
\hline
\end{tabular}

Pode-se notar nesta Tabela que na fração 17 o teor de óxido de cério é de apenas $22 \%$ em peso. Isso se deve ao início da eluição do elemento lantânio, que é o último a ser retirado da resina neste processo de purificação do cério.

Para a obtenção do cério na forma de nitrato, as frações foram 
recolhidas e evaporadas até um volume de $500 \mathrm{~mL}$. Em seguida, foi adicionado ácido nítrico para a formação do nitrato de cério e recuperação do EDTA em solução de pH 1.

Com o objetivo de se avaliar os teores de outras terras raras presentes, duas alíquotas retiradas das frações 12 e 14 foram submetidas a análise por ativação com nêutrons térmicos. Os resultados são mostrados na Tabela III.

Tabela III: Teores (em ppm) de impurezas de Terras Raras. [Table III: Rare Earth impurity contents (in ppm)].

\begin{tabular}{lcc}
\hline Elemento & Fração 12 & Fração 14 \\
\hline $\mathrm{Eu}$ & - & $0,26 \pm 0,04$ \\
\hline $\mathrm{Tb}$ & - & $0,31 \pm 0,09$ \\
\hline $\mathrm{La}$ & $31 \pm 2$ & $40 \pm 5$ \\
\hline
\end{tabular}

A principal impureza detectada, como esperado, é o La que, como mencionado anteriormente, é o último elemento a ser removido.

$\mathrm{Na}$ Tabela IV são mostrados os resultados de análise por espectrometria de plasma de impurezas metálicas no óxido e no nitrato de cério.

Tabela IV: Teores (em \% peso) de impurezas metálicas. [Table IV: Metallic impurity content (in wt\%)].

\begin{tabular}{lcc}
\hline Elemento & $\mathrm{Ce}\left(\mathrm{NO}_{3}\right)_{3} \cdot 6 \mathrm{H}_{2} \mathrm{O}$ & $\mathrm{CeO}_{2}$ \\
\hline $\mathrm{Si}$ & 0,15 & $<0,006$ \\
\hline $\mathrm{Al}$ & 0,03 & $<0,006$ \\
\hline $\mathrm{Mg}$ & $<0,0045$ & $<0,0045$ \\
\hline $\mathrm{Ca}$ & 0,03 & 0,02 \\
\hline
\end{tabular}

Os resultados mostram que as principais impurezas detectadas tanto no óxido quanto no nitrato de cério são $\mathrm{Si}, \mathrm{Al}, \mathrm{Mg}$ e Ca. Pode ser visto também que os teores de silício e alumínio são muito maiores no nitrato do que no óxido de cério. Esta contaminação foi atribuída à etapa de evaporação da solução do complexo EDTATerras Raras, que foi realizada em becker de vidro.

Uma alíquota da fração 16 foi submetida a análise termogravimétrica e o resultado é mostrado na Fig. 5.

A perda de massa ocorre em três etapas, sendo a primeira, até $98^{\circ} \mathrm{C}$, devida à eliminação de água. As outras etapas (entre $100^{\circ} \mathrm{C}$ e $253^{\circ} \mathrm{C}$ ) estão relacionadas com a eliminação de $\mathrm{NO}_{2}$ e de $\mathrm{NO}$. Para temperaturas superiores a $255^{\circ} \mathrm{C}$ a variação de massa é insignificante mostrando que o precursor de cério está praticamente decomposto a esta temperatura.

Após calcinação a $900^{\circ} \mathrm{C} / 1 \mathrm{~h}$ o valor determinado para a superfície específica foi de $2,6 \mathrm{~m}^{2} \cdot \mathrm{g}^{-1}$.

Na Fig. 6 é mostrada uma micrografia obtida em microscópio eletrônico de varredura do óxido de cério.

Neste caso, uma parte da fração 12 foi precipitada com hidróxido de amônio. O gel resultante foi lavado, seco e calcinado a $600{ }^{\circ} \mathrm{C} /$ $1 \mathrm{~h}$ obtendo-se um pó fino de coloração amarelo claro. A forma e o tamanho das partículas/aglomerados é típica do óxido de cério não apresentando diferenças com relação ao material comercial.

Na Fig. 7 é mostrada a distribuição de tamanho de partículas obtida por espalhamento laser para uma amostra calcinada a $900^{\circ} \mathrm{C} / 1 \mathrm{~h}$.

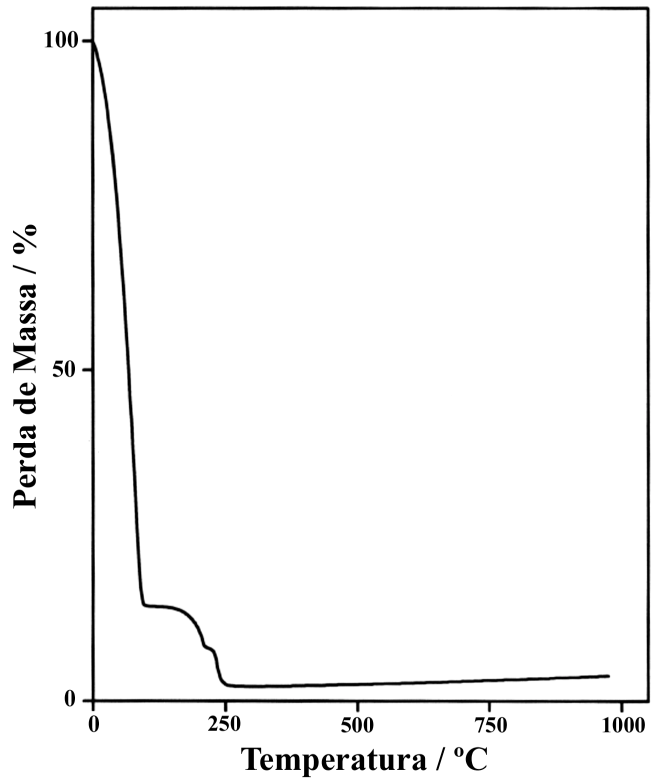

Figura 5: Curva termogravimétrica de uma alíquota da fração 16. [Figure 5: Thermogravimetric curve of a sample from fraction 16].

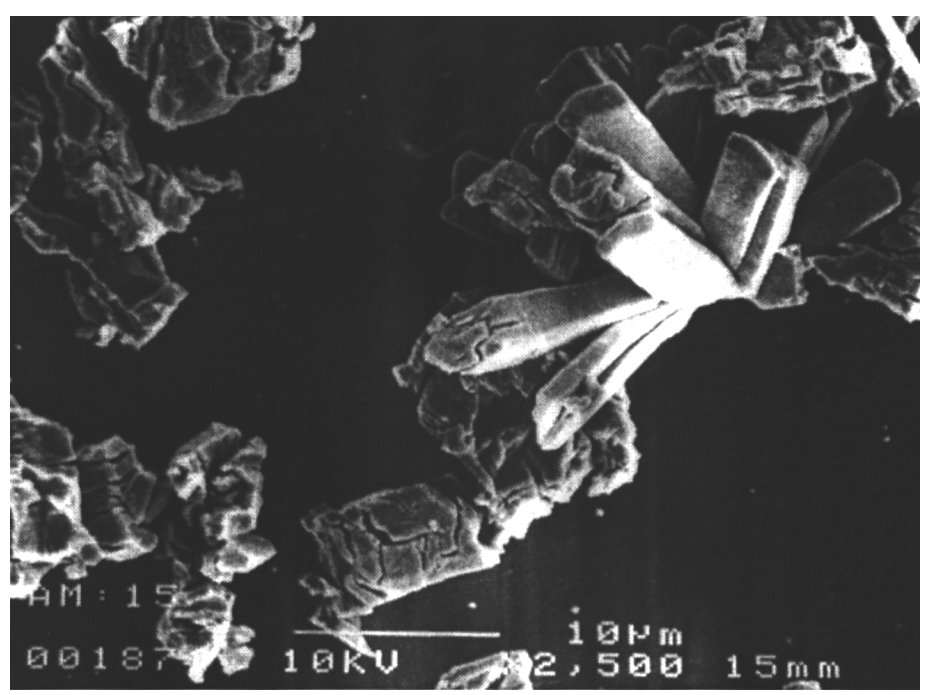

Figura 6: Micrografia obtida em microscópio eletrônico de varredura do óxido de cério. [Figure 6: Scanning electron microscopy micrograph of the synthesized cerium oxide].

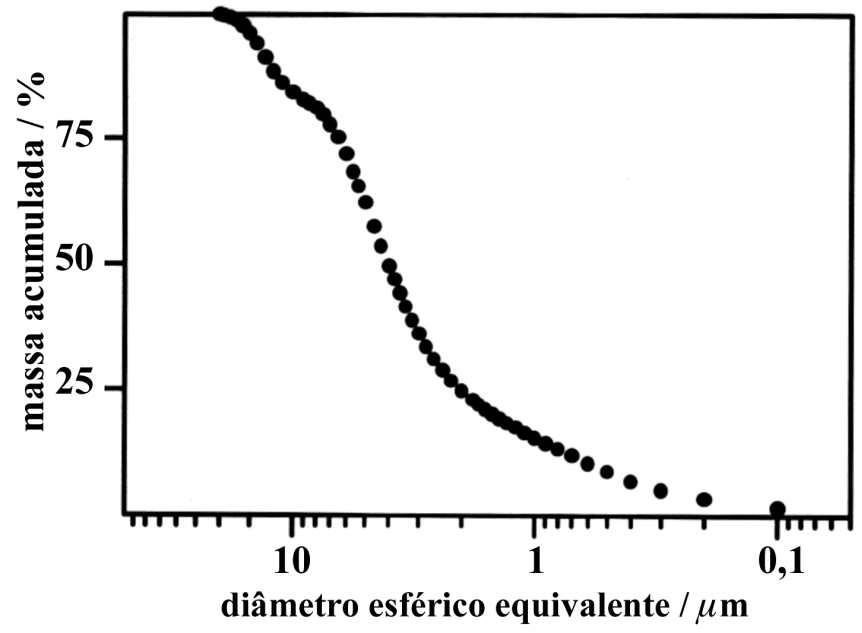

Figura 7: Curva de distribuição de tamanho de partículas para o óxido de cério. [Figure 7: Particle size distribution of cerium oxide]. 
A curva de distribuição de tamanho de partículas mostra que o tamanho máximo é de $\sim 20 \mu \mathrm{m}$, que $50 \%$ das partículas apresentam tamanho inferior a $4 \mu \mathrm{m}$ e que, apesar da dispersão em ultrassom, estão aglomeradas.

\section{SUMÁRIO}

Foram descritas as técnicas de precipitação fracionada e troca iônica, que podem ser juntamente utilizadas na separação e purificação de elementos lantanídeos. Foram também descritas as principais técnicas utilizadas no controle analítico das terras raras. As técnicas descritas são utilizadas no IPEN na preparação destes elementos para uso como padrão espectroquímico. Neste trabalho, as técnicas mencionadas foram empregadas para a obtenção de óxido de cério e nitrato de cério de elevada pureza, para serem utilizados como precursores na preparação de cerâmicas de zircônia-céria ou de céria contendo terras raras.

\section{AGRADECIMENTOS}

Ao D. M. Medeiros pelo auxílio no desenvolvimento deste trabalho. À INB pelo fornecimento do cloreto misto de terras raras. À A. M. G. Figueiredo pelas análises por ativação com nêutrons. À FAPESP (99/04929-5), CNPq, CNEN e FINEP/ PRONEX.

\section{REFERÊNCIAS}

[1] Min. Comm. Summ., US Bureau of Mines (1992).

[2] C. A. S. Queiroz, Terras raras - fracionamento, purificação e controle analítico, Dissertação de Mestrado, USP (1988).

[3] C. A. S. Queiroz, A. Abrão, Anais do $14^{\circ}$ Simpósio Anual da ACIESP, S. Paulo (1990).

[4] D. R. Ricci, J. S. M. Nobre, J. O. A. Paschoal, Anais do $34^{\circ}$ Congresso Brasileiro de Cerâmica, (1990).

[5] C. A. S. Queiroz, E. C. B. Hespanhol, A. Abrão, Anais do $4^{\circ}$ Congresso Geral de Energia Nuclear (1992).

[6] J. D. Lee, Química Inorgânica, Edgar Blücher (1980).

(Rec. 11/10/00, Ac. 02/02/01) 